\title{
Effectiveness of High Voltage in Distribution System: High Voltage Distribution System
}

\author{
Ankita Gupta ${ }^{1}$, Harmeet Singh Gill ${ }^{2}$, Isha Bansal ${ }^{3}$ \\ ${ }_{1,2,3}$ (Department of Electrical Engineering, Guru Nanak dev Engineering College Ludhiana, Punjab, India)
}

\begin{abstract}
This paper presents the comparison of existing low voltage distribution system with proposed high voltage distribution system. The study is based on a real low voltage feeder in $J \& K$ state. The investigation is carried out to determine the losses in the existing low voltage (LT) distribution system and then converting this low voltage distribution system to proposed high voltage distribution system (HVDS) including bifurcation of load and replacing the one large transformer with various transformers of small rating. Since loss reduction in distribution system is of keen importance and main reason behind these losses is the use of low voltage for distribution in existing system. As for the low voltage in existing distribution system, current is high which leads to high power losses and also allow the hooking and hence power theft. This paper aims at reducing losses by using LT less or less LT 'HVDS' system and then determining the reduction in losses in terms of units and annual savings in terms of rupees due to proposed method. To check the feasibility of the proposed work, the annual saving and payback period of the proposed method is also determined.
\end{abstract}

Keywords - Annual saving, Capital outlay, Distribution losses, High Voltage Distribution System, Payback period.

\section{INTRODUCTION}

Economic development of a country depends on the energy availability and its consumption. Electrical energy has played a great role in building up of present day civilization. Electrical energy has made our life easier, comfortable and saves our time. Now there is shorter working day and technology based on electricity resulted in a higher agricultural and industrial production, and better transportation facilities. Even the standard of living of a person is decided by its energy consumption. In fact, the greater the per capita consumption of energy in a country, the higher is the standard of living of its people. Today modern society is so much dependent upon the use of electrical energy that it has become an important part of our life. Earlier it was not so, electricity was used for the basic purpose of light and heat and thus there was little demand for electrical energy and it was easy for the power companies to meet their demand. But in today's modern world, energy demand is increasing day by day and to meet this ever increasing demand power companies are making every effort to increase the energy availability. But the efforts made by the power companies to bridge the gap between energy demand and energy availability are all in vain. Some says the reason behind the lack of availability of energy is, fast depleting energy resources, but this is not true for the developing nation like India where there is treasure of nature. Many states in India still have large amount of unexplored and underutilized resources and this hidden potential is enough to meet the growing energy demand. The root cause of the underutilized resources in India is the lack of commercial viability in power sector and thus less interest of the utilities to invest in the power sector as there is almost no or very low profits. Power companies are in loss because of losses in transmission and distribution system, unauthorized connection, theft and unwillingness to pay bills as some customers have attitude that our government is doing nothing for us, at least they can provide us free electricity and some customers are tired of poor quality of supply and thus do not pay their electricity bill. In fact, India's power sector today is characterized by financial insolvency and an inadequate power supply. Plant availability and efficiency are generally low and the system losses are untenably high specifically at the last mille secondary low tension network. The present power sector is like a leaking bucket and the efforts made by the government and power companies to generate more electrical power in this leaked sector are nothing but ways of pouring more water into the leaked bucket so that the consistency and quantity of leaks are assured. The logical thing to do would be to fix the bucket i.e. make the system leak proof rather than to persistently emphasize shortages of power and forever make exaggerated estimates of future demands for power and only then investing in generating more power will be of worth. As once the utilities will get back more than what they are investing in the power project, then the problem of underutilized resources will be no more and then there will be light for every house. But efforts should be made on both sides i.e. at utility end as well as at the consumer end. Hence both commercial viability of power sector and consumer satisfaction hand in hand will make a healthy system and then only the gap between energy demand and energy availability will be bridged. In this paper, main focus is given on the reduction of distribution losses and improves the power quality in the present existing system to bring the commercial viability in the power sector. 


\section{DISTRIBUTION SYSTEM}

The primary and secondary power distribution network, which generally concerns the consumer in India, is the distribution network of $11 \mathrm{kV}$ lines or feeders downstream of the $33 \mathrm{kV}$ substation. Each $11 \mathrm{kV}$ feeder which emanates from the $33 \mathrm{kV}$ substation branches further into several subsidiary $11 \mathrm{kV}$ feeders to carry power close to the load points (localities, industrial areas, villages, etc). At these load points, a transformer further reduces the voltage from $11 \mathrm{kV}$ to $415 \mathrm{~V}$ to provide the last-mile connection through $415 \mathrm{~V}$ line also called as Low Tension (LT) line to individual customers, either at $240 \mathrm{~V}$ as single-phase supply or at $415 \mathrm{~V}$ as threephase supply. A feeder could be either an overhead line or an underground cable. In urban areas, owing to the density of customers, the length of an $11 \mathrm{kV}$ feeder is generally up to $3 \mathrm{kms}$. On the other hand, in rural areas, the feeder length is much larger even up to $20 \mathrm{kms}$. A $415 \mathrm{~V}$ line should normally be restricted to about $0.5-1.0$ $\mathrm{km}$. In existing distribution systems, the voltage at buses reduces when moved away from the substation, also the losses are high. The reason for high losses is the use of low voltage for distribution as the current is high in the low voltage system and thus more losses. Thus by using high voltage for distribution we can reduce the losses as current in high voltage distribution system (HVDS) is low. In the existing system pilferage is very easy because of lengthy bare LT conductor, and thus many unauthorized connections are tapped from the bare LT conductor.

\section{LOSSES IN THE DISTRIBUTION SYSTEM}

The losses prevailing in the existing power distribution system can be classified as: a) Technical losses b) Non-Technical losses. Technical losses on distribution system are primarily due to heat dissipation resulting from current passing through conductors and magnetic losses in transformers. Technical losses occur during transmission and distribution involves substation, transformer, and line related losses. These include resistive losses of the primary feeders, the distribution transformer losses (resistive loses in windings and the core losses), resistive losses in secondary network, resistive losses in service line and losses in KWh meter. These losses are inherent to the distribution of electricity and cannot be eliminated but can be reduced. Non-Technical losses include tampering with the meter to create false consumption information used in billings, making unauthorized connections to the power grid. Non-payment, as the name implies, refers to cases where customers refuse or are unable to pay for their electricity consumption. It is estimated that electricity theft costs in India is in crores in a year. Non-Technical losses (NTL) include electricity theft. Electricity theft is defined as a conscience attempt by a person to reduce or eliminate the amount of money he will owe the utility for electric energy. It can be done by tampering with the meter to create false meter reading i.e. create false consumption information used in billings, meters not read, non performing and under performing meters, making unauthorized connections and direct tapping. Non-payment, as the name implies, refers to cases where customers refuse or are unable to pay for their electricity consumption. It is estimated that electricity theft costs in our country is in crores in a year. Both the technical and non-technical losses are together termed as T\&D (transmission and distribution) losses. In India, average T\&D losses are estimated as $23 \%$ of the electricity generated. But in actual practice these losses are as high as 50\% in some states of India. In addition to above two types of losses, there is also a loss in revenue due to non realization of revenue billed and the aggregate of all these losses is termed as AT\&C (aggregate technical and commercial) losses. For this issue, Electricity Board is trying to draw attention to the need for reforms in electricity transmission and distribution sector, create mass awareness about transmission losses due to theft and misuse of electric energy. Also effective checks and balances in power distribution at various levels are imperative and to strictly implement timely revenue collection. And thus it is necessary to focus on both side i.e. on technical losses as well as on non-technical losses and it can be achieved by using proposed HVDS method for distribution. The main advantage of using high voltage for distribution is to reduce the theft of energy and decrease in unauthorized connection as the LT lines are virtually eliminated and even short LT lines required will be with insulated cables i.e. ABC. This makes direct tapping very difficult and thus increases the authorized connection which will improve revenue. Also the current in the proposed method is low due to high voltage and thus low power losses. It also helps in avoiding unnecessary iron losses in overrated distribution transformer which otherwise occur in the existing system and hence reduces technical losses.

\section{REASONS OF HIGHER LOSSES}

To understand the method to reduce the losses, it is necessary to look for various reasons for higher losses in the existing system. The main reasons are:

a. Lengthy distribution lines

b. Inadequate size of conductors

c. Over-rated distribution transformers and hence their under utilization

d. Low voltage (less than declared voltage) appearing at transformers and consumers terminals

e. Distribution transformer not located at load center on the secondary distribution system

f. Low power factor

g. Poor HT/LT ratio

h. Poor quality of equipments 
i. Too many stages of transformations

j. Transformer Losses

k. Bad workmanship

1. Direct tapping by the non-customers

m. Pilferage by the existing customers

n. Defective metering, billing and collection functions

\section{LOSS REDUCTION TECHNIQUES}

To reduce the distribution losses, many techniques are developed and some of the loss reduction approaches are given below

a) Network reconfiguration and Phase Load Balance

b) Automatic voltage booster

c) Network reconductoring

d) Distribution Transformers Locating and Sizing

e) High-efficient Transformer

f) Reactive Power Compensation

g) High voltage distribution system (HVDS)

h) Aerial Bunched Cables (ABC)

Earlier work on loss reduction has done by using capacitor setting/switching and network reconfiguration using branch exchange method and also on the combination of network reconfiguration and reactive power control using capacitor placement technique and a very few on loss reduction using HVDS system. In this research paper, HVDS technique is adopted to reduce the losses in existing low voltage distribution system by converting it into a high voltage distribution system. Main aim is to compare the existing LT distribution system to the HVDS system in term of losses (i.e. both power losses and transformer losses) and to determine the annual saving and thus payback period. Under this system HT line is extended up to or as near the load as possible and to erect small capacity distribution transformers i.e. $10 \mathrm{KVA}, 15,25 \mathrm{KVA}$ etc and to extend supply to the consumer through a short length of LT lines, preferably insulated overhead cable system. Due to use of smaller rating transformers, either three phase or single phase length of LT lines is considerably reduced and power is distributed mainly through $\mathrm{HV} 11 \mathrm{kV}$ lines.

\section{HIGH VOLTAGE DISTRIBUTION SYSTEM (HVDS)}

HVDS project is to reconfigure the existing Low voltage (LT) network as High Voltage Distribution System, wherein the $11 \mathrm{kV}$ line is taken as near to the loads as possible and the LT power supply is fed by providing appropriate capacity transformer and minimum length of LT line with an objective to provide better quality power supply, reduction of losses and better consumer service. In the existing system, large capacity transformers are provided at one point and the connections to each load is extended through long LT lines. This long length of LT lines is causing low voltage condition to the majority of the consumers and high technical losses. In the HVDS project, long length LT mains are converted into $11 \mathrm{kV}$ mains and thereby installing the appropriate capacity distribution transformer as near as to the end and the supply is provided to the consumer at suitable voltage level. By converting these lines to HVDS, the current flowing through the lines shall reduce by 28 times and will bring down the technical losses in the LT line drastically. This can be explained by one single illustration that for a $100 \mathrm{KVA}$ load the amperage at $11 \mathrm{kV}$ is 5 amperes where as it is 140 amperes at LT voltage of 415 Volts. The prevailing low voltage in the LT line is also affecting the efficiency of the electric gadgets and breakdown is also very high. Also there is a tendency of unauthorized connections to hook to the LT lines which results in over loading of the transformers and failure of the transformers. The scheme consists of converting the existing 3 phase 4 wires lines to $11 \mathrm{kV}$ systems using the existing supports and providing intermediate poles wherever necessary and individual transformers are provided to both agricultural loads and loads other than agriculture. The length of the LT lines is restricted to less than 300 meters. HVDS is most effective method in reducing the technical losses and improving the quality of supply in power distribution system. In this system high voltage lines are extended to as nearer to the loads as possible and erect small size transformers. This system aims at LT less system or less LT and the unavoidable short LT lengths to be covered by insulated wires like ABC (Aerial Bunched Cables). The major advantages of using ABC in HVDS are that the faults on LT lines are totally eliminated, thus improving reliability and also theft by direct tapping is avoided. As the authorized consumers do not allow unauthorized tapping by another as their transformer gets overloaded or may get damaged, resulting in outage of power supply for longer durations. Based on the feedback received from Andhra Pradesh and Greater Noida where HVDS schemes have been operational in urban and rural applications. It is noticed that the investment on conversion from conventional system to HVDS is recovered by way of loss reduction within a period of 3 to 5 years in most cases. There are three types of High Voltage Distribution System namely, Single phase and single neutral, two phase two wire and three phase small rating transformer with three phase HV system. 


\section{1. $\quad$ Bifurcation Of Load And Calculation Of Power Losses}

Annual power losses in the LT line and HT line in terms of KW and units is calculated by using the (1) and (2) respectively. Load bifurcation and selection of small and appropriate size of DTs in the proposed high voltage distribution system is shown in Table 6.1. This data has been taken from a low voltage $11 \mathrm{kV}$ feeder in Jammu and Kashmir state where the power sector is one of the most underdeveloped sector and implementation of proposed scheme will provide fruitful results in distribution area.

TABLE 6.1 LOAD BIFURICATION IN HVDS SCHEME

\begin{tabular}{|c|c|c|c|c|c|c|c|c|c|c|}
\hline \multirow[t]{2}{*}{$\begin{array}{l}\text { S. } \\
\text { No. }\end{array}$} & \multirow[t]{2}{*}{$\begin{array}{l}\text { Name of } \\
\text { substation }\end{array}$} & \multirow{2}{*}{$\begin{array}{l}\text { Load } \\
\text { in } \\
\mathrm{KV} \\
\mathrm{A}\end{array}$} & \multirow{2}{*}{$\begin{array}{l}\text { Sanctio } \\
\mathrm{n} \text { Load } \\
\text { in KW }\end{array}$} & \multirow{2}{*}{$\begin{array}{l}\text { Lengt } \\
\mathrm{h} \text { of } \\
\mathrm{LT} \\
\text { line }\end{array}$} & \multirow{2}{*}{$\begin{array}{l}\text { No. of } \\
\text { consum } \\
\text { er }\end{array}$} & \multicolumn{4}{|c|}{$\begin{array}{l}\text { No. of DT required for } \\
\text { HVDS }\end{array}$} & \multirow[t]{2}{*}{ Total } \\
\hline & & & & & & $\begin{array}{l}6.3 \\
\mathrm{KV} \\
\mathrm{A}\end{array}$ & $\begin{array}{l}10 \\
\mathrm{KV} \\
\mathrm{A}\end{array}$ & $\begin{array}{l}15 \\
\mathrm{KV} \\
\mathrm{A}\end{array}$ & $\begin{array}{l}25 \\
\text { KVA }\end{array}$ & \\
\hline 1 & S1 & 25 & 12 & 0 & 12 & & & 2 & & 2 \\
\hline 2 & S2 & 400 & 148 & 0.05 & 136 & 8 & 8 & 10 & 5 & 31 \\
\hline 3 & S3 & 250 & 116.5 & 0.036 & 147 & 15 & 10 & 5 & & 30 \\
\hline 4 & S4 & 25 & 16.7 & 0.05 & 16 & & 3 & & & 3 \\
\hline 5 & S5 & 630 & 319.15 & 0.027 & 233 & & 5 & 15 & 15 & 35 \\
\hline 6 & S6 & 25 & 12 & 0 & 10 & & & 2 & & 2 \\
\hline 7 & S7 & 25 & 11.05 & 0 & 9 & & & 2 & & 2 \\
\hline 8 & S8 & 100 & 67.06 & 0.056 & 70 & 10 & 4 & & & 14 \\
\hline 9 & S9 & 25 & 19.2 & 0.099 & 21 & & 3 & & & 3 \\
\hline 10 & S10 & 400 & 180 & 0.2 & 231 & & 15 & 10 & 5 & 30 \\
\hline 11 & S11 & 400 & 105 & 0.025 & 125 & & 15 & & 10 & 25 \\
\hline 12 & S12 & 25 & 10 & 0 & 8 & & & 2 & & 2 \\
\hline 13 & S13 & 25 & 12 & 0 & 10 & & & 2 & & 2 \\
\hline 14 & S14 & 500 & 242.8 & 0.177 & 307 & 20 & 15 & 10 & 5 & 50 \\
\hline & & & & & & & & & & 231 \\
\hline
\end{tabular}

Line loss in $\mathrm{KW}=\left[\left\{(\mathrm{Cum} \text { load in } \mathrm{KVA} /(1.732 \times \text { voltage in } \mathrm{KV} \times \mathrm{DF})\}^{\wedge} 2 \times\right.\right.$ Length in Km $\times$ Resistance constant $/ 1000$

Line loss in Units $=[\{($ cum load in KVA/ $(1.732 \times$ voltage in $\mathrm{KV} \times \mathrm{DF})\} \wedge 2 \times$ Length in $\mathrm{Km} \times$ Resistance

Where

constant $\times$ LLF $\times 8760] / 1000$

Voltage $=11 \mathrm{KV}$ for HT line

$$
=0.4 \mathrm{kV} \text { for LT line }
$$

Diversity factor $(\mathrm{DF})=1.5$ for HT line

$$
=1.1 \text { for LT line }
$$

Load Factor $(L F)=$ Annual Energy consumption $/($ Peak $\times 24 \times 0.9 \times 365 \times 1000)$

$$
\begin{aligned}
& =0.18 \text { for HT line } \\
& =0.36 \text { for LT line }
\end{aligned}
$$

Line Loss Factor $(\mathrm{LLF})=(0.2 \times \mathrm{LF})+\left[0.8 \times\left(\mathrm{LF}^{\wedge} 2\right)\right]$

$$
\begin{aligned}
& =0.36 \text { for HT line } \\
& =0.18 \text { for LT line }
\end{aligned}
$$

\subsection{Comparison Of Existing LT System And Proposed HVDS System And Annual Saving And Payback Period}

Reduction in losses, annual saving and payback period is given in (3), (4) and (5) respectively. The results so obtained in this paper including comparison of existing LT system and proposed HVDS system and reduction in losses in terms of units is shown in Table 6.2.

Reduction in losses $=$ Losses in existing low voltage system - Losses in HVDS

Annual Savings $=$ Price of a unit $\times$ reduction in losses in terms of unit

Payback Period $=($ Capital Outlay $\div$ Annual Savings $)$

In this scheme, total capital outlay is estimated as $=195.865$ lakhs

Annual savings $=$ Annual loss reduction in units $\times$ Unit price

$$
\begin{aligned}
& =34.53 \times 2.50 \\
& =86.325 \text { lakhs }
\end{aligned}
$$

Payback period $=$ Total capital outlay $/$ Annual savings

$$
=195.865 \text { lakhs } / 86.325 \text { lakhs }
$$

$=2.27$ years 
Effectiveness Of High Voltage In Distribution System: High Voltage Distribution System

TABLE 6.2 Comparison of Existing LT System and Proposed HVDS System

\begin{tabular}{|c|c|c|c|c|}
\hline S.No. & $\begin{array}{l}\text { Name of the } \\
\text { transformer }\end{array}$ & $\begin{array}{c}\text { Before } \\
\text { Improvement }\end{array}$ & $\begin{array}{c}\text { After } \\
\text { Improvement }\end{array}$ & $\begin{array}{c}\text { Reduction in Losses } \\
\text { in units }\end{array}$ \\
\cline { 3 - 4 } & & Line losses in units & Line losses in units & \\
\hline 1 & T1 & 174.858 & 0.1899 & 174.668 \\
\hline 2 & T2 & 59686.72 & 478.722 & 59207.998 \\
\hline 3 & T3 & 27214.77 & 209.379 & 27005.391 \\
\hline 4 & T4 & 390.755 & 5.4968 & 385.258 \\
\hline 5 & T5 & 291811.908 & 1227.089 & 290584.819 \\
\hline 6 & T6 & 146.612 & 0.1593 & 146.453 \\
\hline 7 & T7 & 106.449 & 0.1364 & 106.313 \\
\hline 8 & T8 & 6384.859 & 98.0578 & 6286.80 \\
\hline 9 & T9 & 447.637 & 14.0231 & 433.614 \\
\hline 10 & T10 & 68104.488 & 2503.192 & 65601.296 \\
\hline 11 & T11 & 23602.933 & 156.766 & 23446.167 \\
\hline 12 & T12 & 77.894 & 0.122 & 77.772 \\
\hline 13 & T13 & 134.506 & 0.146 & 134.36 \\
\hline 14 & T14 & 298353.886 & 4056.499 & 294297.387 \\
\hline \multicolumn{2}{r|}{ TOTAL } & 3461838.275 & 8749.947 & 3453088.325 \\
\hline
\end{tabular}

VII. CONCLUSION

In this paper, it is concluded that with the adoption of high voltage for distribution i.e. HVDS both the technical as well as non-technical losses are reduced. Firstly as in HVDS, the registered customers will feel ownership and take responsibility and not allow others to meddle with the LT Network and even prevent unauthorized loads by the consumers themselves since the distribution transformer may fail if loaded beyond its capacity which reduces the failure rate because of no over loading and no meddling of LT Lines and failure if occur will affect only two or three customers instead of 25 to 30 customers in original system. Secondly, the use of high voltage for distribution in HVDS results in reduction in losses and improves the HT:LT ratio and hence improves quality of supply as it is a LT less or less LT system and thus there is practically less or no voltage drop in LT side and consequent savings in power purchase cost. It will also improve the voltage profile and there will be less burnout of motors because of good voltage and less fluctuation. Last but not least it provides better accountability at all level and effective solution to consumer's enquiry and also results in accurate and reliable energy accounts on sustainable basis.

\section{References}

[1] Essa-J-Abdul Zehra, Mahmoud Moghavvemi, Maher M. I. Hashim and Kashem, Muttaqi, Network Reconfiguration Using PSAT for Loss Reduction in Distribution Systems, 1st International Conference on Energy, Power and Control (EPC-IQ), College of Engineering, University of Basrah, Iraq, 2010, 62-66.

[2] L.Ramesh, S.Ravindiran, S.P.Chowdhury, S.Chowdhury, Y.H.Song and P.K.Goswami, Distribution System Loss Minimization and Planning using Cymdist, $42^{\text {nd }}$ International Universities Power Engineering Conference (UPEC), University of Brighten, Brighten, UK,2007,316-321.

[3] Arefi Ali , Haghifam Mahmood-reza, Yavartalab Akbar, Olamaei Javad and Keshtkar Hessam, Loss reduction planning in electric distribution networks of IRAN until 2025, $16^{\text {th }}$ conference on Electric Power Distribution Network (EPDC), Bandar Abbas , Iran, 2011, 1-6.

[4] Yang Lin and Guo Zhizhong, Reconfiguration of Electric Distribution Networks for Energy Losses Reduction, $3^{\text {rd }}$ International conference on Electric Utility Deregulation and Restructuring and Power Technologies (DRPT), Nanjing, China, $2008,662-667$.

[5] Juan Carlos Olivares, Yilu Liu and Jose M. Cañedo, Reducing Losses in Distribution Transformer, IEEE transactions on power delivery, 18(3), July 2003, 821-826.

[6] Dong Zhang, Zhengcai Fu, and Liuchun Zhang, Joint Optimization for Power Loss Reduction in Distribution Systems, IEEE transaction on Power Systems, 23(1), 2008, 161-169.

[7] R. Srinivasa Rao, An Hybrid Approach for Loss Reduction in Distribution Systems using Harmony Search Algorithm, International Journal of Electrical and Electronics Engineering, 2010, 462- 467.

[8] Sameer S. Mustafa., Mohammed H. Yasen, Hussein H. Abdullah and Hadi K. Hazaa, Evaluation of Electric Energy Losses in Kirkuk Distribution Electric System Area, Iraq J. Electrical and Electronic Engineering,7(2), 2011, 144-150.

[9] Thomas Nippert, Kathrin Steinke, Martin Schrors, Loss Reduction in High Voltage Urban Distribution Systems, $19^{\text {th }}$ International conference on Electricity Distribution, session 3, Vienna, Austria, Paper No. 719, 2007, 1-4.

[10] Best practices in distribution loss reduction: reference book, Power Development Department (PDD), J\&K, Jammu, 2007.

[11] Flávio V. Gomes, Sandoval Carneiro Jr., Jose Luiz R. Pereira, Marcio P. Vinagre,, Paul Augusto N. Garcia, Edimar J. Oliveira and Leandro R. Araujo, A New Distribution System Reconfiguration Approach Using Optimal Power Flow Technique and Sensitivity Analysis for Loss Reduction, Panel Session: Advanced Models for Distribution System Analysis, IEEE PES General Meeting San Francisco, CA, USA, 1, 2005, 897-901.

[12] M.V. Deshpande, Electrical Power System Design (New Delhi: TATA McGraw-Hill Publishing Company Limited).

[13] B.R.Gupta, Power System Analysis and Design (New Delhi: S. Chand \& Company Limited).

[14] V.K. Mehta and R. Mehta, Principles of Power System (New Delhi: S. Chand \& Company Limited, 2008).

[15] B.L. Theraja, and A.K. Theraja, A textbook of electrical technology, Transmission, distribution and utilization in SI system of units, volume III (New Delhi: S. Chand \& Company Limited, 2005) 